\title{
The Correlational Study of the Personality Traits, Organizational Commitment and Self-Efficacy of Saving and Credit Co-Operative Societies (SACCOS) Employees of Kathmandu
}

\author{
Dess Mardan Basnet ${ }^{1 *}$, Murari Prasad Regmi² \\ ${ }^{1}$ Pacific Academy of Higher Education and Research University, Udaipur, India \\ ${ }^{2}$ Central Department of Psychology, Tribhuvan University, Kathmandu, Nepal \\ Email: *dmbasnet@worldwithoutanger.org
}

How to cite this paper: Basnet, D.M. and Regmi, M.P. (2019) The Correlational Study of the Personality Traits, Organizational Commitment and Self-Efficacy of Saving and Credit Co-Operative Societies (SACCOS) Employees of Kathmandu. Open Journal of Business and Management, 7, 455-479. https://doi.org/10.4236/ojbm.2019.72031

Received: January 18, 2019

Accepted: March 4, 2019

Published: March 7, 2019

Copyright $\odot 2019$ by author(s) and Scientific Research Publishing Inc. This work is licensed under the Creative Commons Attribution International License (CC BY 4.0).

http://creativecommons.org/licenses/by/4.0/

\begin{abstract}
This research is about the study of the Saving and Credit Co-operative Societies (SACCOS) employees' personality traits, self-efficacy, and organizational commitment of Kathmandu district. The researchers have used Mini-IPIP five-factor model personality. The scale consists of 20-items short form of the 50-items IPIP-FFM. The Big Five personality traits have measured employee's agreeableness, conscientiousness, emotional stability, extraversion and intellect. The Organizational commitment scale is used to measure the employee's affective, normative and continuance commitment. The employees are human capital and without their contribution, no one can imagine of this present digital world. The Self-efficacy scale is used to find the optimistic beliefs of employees' competence to deal efficiently with a variety of stressful situations. The total sample size consists of 260 employees $($ Male $=127 \&$ Female $=133$ ). The samples are drawn from Sixty Three SACCOS of Kathmandu district only. This study finds the relationships among the SACCOS employees' personality traits, commitment and self-efficacy to handle the employees' behavior efficiently for the overall productivity of an organization.
\end{abstract}

\section{Keywords}

Personality Traits, Self-Efficacy, Affective, Normative and Continuance, Employees

\section{Introduction}

The history of the Co-operative is a term derived from a social enterprise or 
community-based organization integrated in the service to its members to meet their economic, social and cultural needs and aspirations through a jointly owned and democratically-controlled enterprise.

It shows that the cooperative societies help in improving the living standards, and quality of life, along with good educational outcomes for their children in the semi-urban and rural areas and improve the living standards of low-income and marginalized groups in Nepalese societies. There are about 6,030,857 cooperative members and 56,475 employees with more than 34,500 Co-operative institutions (Co-operative Statistics, 2016, p. 7), involving in operation successfully.

In human resource behavior, personality traits, organizational commitment and self-efficacy are widely studied topics in numerous disciplines, but they pose a deep concern in organizational psychology. Personality traits have significant role in the testing in employee's selection and implementing various personality assessments in the workplace [1]. This study is helpful to explore the knowledge about links with many employees' behaviors and attitudes that may influence the organization like "Big Five" which means five personality traits: agreeableness, conscientiousness, emotional stability, extraversion and intellect that serve as the focus for personal characteristics [2], absenteeism [3], turnover [4] [5], and organizational citizenship behavior [6] and job satisfaction[7]. Carl Gustav Jung (1926-1994) [8] believes the self as an archetype propelled men to search for unity, harmony, and wholeness among all elements of the personality. He gave a start for the studies about personality types and models. Goldberg's list of the best measure of personality trait being used as Big Five, originally consisting of 100 items (Big Five Factor Markers); or the 20-item Mini-IPIP inventory being used short version of the 50 -item questionnaire for scaling the Big Five Personality Traits [9]. The 20-item Mini-IPIP is derived from International Personality Item Pool (IPIP). Lawrence describes that personality refers to the pattern of behaviors consistently exhibited by an individual. This study explores the personality traits and their relationship with self-efficacy and organizational commitment in SACCOS's employees. The study also explores the relationships with the inter co-relationships among the personality traits. Gelade, Dobson, and Gilbert [10] have examined organizational commitment in a sample of 49 countries. Affective commitment (AC) varies significantly by country, and it is strongly related to the dimensions of personality. AC is high in countries where the population is extravert and Low in the Countries where the population is neurotic. Extraversion is a personality trait associated with the positive effect, correlated (0.22) with organizational commitment and emotional stability.

Personality shows the individual differences in characteristic patterns of thinking, feeling and behaving. A galaxy of personality traits are needed for the success in the context of job. The traits are self-awareness, resilience, motivation, interpersonal sensitivity, influence, decisiveness and integrity. According to Church [11] traits are comparatively stable in individual differences in thoughts, feelings and behaviors. Personality has central role in this research. Its accuracy 
of measurement depends on the selection of empirically reliable tools. Effective management of emotion is the key part of emotional intelligence. An employee should understand emotional messages in the regulation process of emotions and one's own and others' emotions. This model combines emotional self-perceptions and emotional traits describe person's own traits. This model of emotional intelligence can only be viewed in conjunction with a comprehensive exploration of person's personality. The Mini-IPIP personality scale was developed as a 20 -item short form of the 50-item IPIP-FFM. The noted psychologist, like Goldberg pioneered the researches in IPIP Big Five.

Allen and Meyer [12] [13] define that organizational commitment as a "psychological link between the employee and his or her organization makes it less likely that the employee will voluntarily leave the organization. Organizational commitment is not only a significant factor in human resource management but also a widely studied topic, and a deep concern in organizational psychology due to its connection with many employees' behaviors and attitudes. Numerous definitions of the organizational commitment state that all commitments are like a psychological state that describes an employee's relationship with organization and a tendency to continue the relationship with the organization [14]. The loyal and committed employees of an organization create values, dedication and strong belief among the team members. The employees have commitment to foundational roles to achieve the specific organizational goals. The organizational commitment exists in the three types of the commitment in organization. Meyer and Allen furthermore, have developed a three-dimensional model encompassing affective, normative, and continuance commitment. Affective commitment defined by Meyer and Allen, as the "emotional affection to an organization; a strong belief in and reception of the organizations' goals and values which result in willingness to exercise most favorable effort to attain the organizational goals". Normative commitment is "an employee's feeling of compulsion to carry on working for an organization". The third component, continuance commitment refers to "the longing to continue membership in an organization for the fright of forfeiting values as rewards".

Bandura [15] [16] [17] defines the self-efficacy as a personal belief, that influences one's behavior, way of thinking and emotional reactions in a difficult situation. He further states that theories and researches of self-efficacy create a difference in how people feel, think, and act. In terms of feeling, a low sense of self-efficacy is associated with depression, anxiety, and helplessness. Luszczynska, \& Schwarzer [18] describe that self-efficacy affects every area of human endeavor. Gungor, Kurt, and Ekici [19], explain that personality factors have an effect on personal traits of the students. Some qualitative studies define that there is a relationship between personality types and sense of expression of the respondents' efficacy. [20] found positive self-efficacy in employees because of the availability of resources and high levels of self-efficacy in employees. Similarly [21] describes entrepreneurs and employees are often more engaged, moti- 
vated and, consequently, successful in their tasks due to the high levels of selfefficacy and sufficient amount of resources in the organization. Kossowska \& Laguna [22] found that the result of hierarchical regression analyses have shown conscientiousness, skill variety and self-efficacy are statistically significant predictors of volunteer non-profit organization of Poland.

Recently, Farrukh, Ying, and Mansori [23] have expressed that extroversion, agreeableness, and conscientiousness are positively associated to affective commitment and openness or intellect and emotional stability are negatively linked with affective commitment. Farruk et al. [24] have found that emotional stability negatively correlated with continuance commitment. Likewise, there was no relationship between continuance commitment with conscientiousness and openness personality trait. Furthermore, extraversion, and agreeableness were found to be negatively associated to continuance commitment. The previous study of Basnet (2018) has reported similar result as emotional stability is negatively correlated with affective commitment. Similarly, agreeableness, conscientiousness and intellect trait are highly correlated to affective commitment. These results showed that personality traits as a whole are significantly associated with organizational commitment. Agreeableness trait is the strongest predictor of both affective and continuance commitment. Agreeableness trait is especially relevant to predict employees' outcomes which are subject to strong interpersonal or social relationships. Such outcomes are vital for the survival of more and more employees', group and for their organizational effectiveness.

Some personality traits either positively or negatively correlated with the organizational commitments and self-efficacy. This study also examines the impact of personality on the self-efficacy of the SACCOS employees. This research analyses the differences between male and female of SACCOS's employees. The personality traits are consistent and durable of an individual who makes him or her different from each other. The loyal and committed employees are able to exhibit values, dedication and strong beliefs among the fellow workers at workplace.

\section{Review of the Literature}

Many literature reviews have discussed the various dimensions about the personality traits but still the five-factor model (FFM) is the most prominent model to assess human behavior in workplace in anytime, place, and culture. FFM consists of five factors such as extraversion (sociable vs. introverted) agreeableness (cooperative vs. competitive), emotional stability (emotional stability vs. instability) openness (intellectual curiosity vs. preference for routine), and conscientiousness (organized vs. careless) personality trait.

The "Five Factor Theory" has developed by Norman [24]. Goldberg, McCrae \& John [25] have conceptualized that FFM was one of the best tools to assess the employees personality traits, but FFM is actually first introduced by the noted scholar Thurstone. McCrae and Costa have said that the personality traits are 
dimension of individual differences in tendencies to demonstrate consistent patterns of thoughts, feelings, and actions". The Big Five personality traits are five broad domains that used to describe personality of Nepali Civil Servant Employees [26]. FFM has been developed into one of the most established avenues extensively that elaborate the most significant factors of individuals' personality. People's cognitive and, affective and motor responses are important to the organizational change determined by their personalities.

The extraversion trait indicates individuals' tendency to be socially more active and reactive as they develop more social networks compared to those who are low in this dimension [27] [28]. The previous empirical studies recognized that higher levels of interaction pose the frequency and scope of using more networking behaviors [29]. Therefore, individuals who score high in extraversion are expected to establish high in social networks with other organizations [30]. John \& Srivastava [2] have explained that the degree, to which an individual is tense, means their worries are more than others and they tend to be moody. Many past studies have showed employees scoring high in emotional stability are highly motivated by and attracted to their hygiene factors, such as job security, benefits, pay, work conditions [31]. Becker [32] has already explained that employees' remuneration, specific skills, work security, and work friends are helpful fundamental reasoning for continuing their job. If they made a decision to quit their existing job, all of these will be sacrificed including their previous work background, hard work, and experiences. Thus, it creates a positive relationship between neurotic tendency and continuance commitment. Erdheim et al. [27] have viewed that neurotic experience of higher anxiety about facing a new work environment that leads to harsher experiences when negative events exhibit in their jobs.

In Nepal, researches in personality psychology were pioneered by M.P. Regmi [33] [34] [35]. FFM has been practicing in various organizational programs such as emotional intelligence, selection and recruitment, and performance. Personality traits help to develop people's characteristic patterns of feelings, thoughts, and behaviors defined as psychological aspects. Personality traits become one of the main factors that affect human behavior due to the impact on controlling the people's reaction to bring changes in the organization. People's behaviors, as well as cognitive and affective responses to the organization are determined by their modification in their personalities.

According to Ying \& Ahmad, personality traits are associated to link with employees' attitude within the organization. The personality factors of employees were tested during their recruitment and practicing of the various assessments or roles in the organizations. The personality dimensions are used to assess in the organizational development and applied in the multiple levels of analysis, beside that human resource practices are commonly used as an individual variable. The interesting fact was found in an empirical study by Spagnoli and Caetano [36]. The trait of the extraversion was correlated positively to the normative, continuance and affective commitment. Thus, the personality factors of 
openness to experience, Emotional stability, and conscientiousness are significantly correlated to the continuance, while commitment and agreeableness are significantly related to the normative commitment. Meanwhile, a study identified by Tziner et al. [37] have found positive strong relationship with the conscientiousness, agreeableness, and openness to experience are significant and positively related to organizational commitment.

Choi, Oh, \& Colbert [38] observes the relationships between the Five-factor model (FFM) of personality traits and three forms of organizational commitment (affective, normative, and continuance) and their variability across individualistic and collectivistic cultures. All FFM traits have positive relationships with affective commitment and normative commitment. The traits of emotional stability, extraversion, and openness to experiences have negative relationships with continuance commitment. In particular, affective and normative commitment have strongly related to agreeableness trait.

Subedi [26] explains that the trait of emotional stability in the Big Five personality dimensions showed significant differences between the two ranks of the officer level $(\mathrm{M}=61.33, \mathrm{SD}=9.787)$ and the non-officer level $(\mathrm{M}=69.99, \mathrm{SD}=$ $12.170), \mathrm{t}(298)=6.79, \mathrm{p} \leq 0.001$. He further indicates that the emotional stability level of non-officer is higher than that of the officer level. His further study has identified that except for the emotional stability trait, all the other personality traits found higher mean scores for non-officers than officers. The results of this study are helpful to relate the Nepalese SACCOS employees for further investigation of the researchers. Subedi [26] observes that there is a relationship between Big Five personality traits and job satisfaction of the Nepalese Civil Servants, where the beta coefficient was positive $(p=0.021<0.05)$, is significant at 0.05 level. Farrukh, Ying, and Mansor [23] have found extraversion, emotional stability, conscientiousness, intellect and agreeableness show significant effect on employees' job satisfaction. The above studies of job satisfaction with big five personality traits exhibit similar results. Stewart and Nandkeolyar [39] state that employees, with a greater degree of openness deserve opportunities to deal with uncertain situations and to learn new beliefs, are likely to achieve higher job efficiency.

Ganu \& Kogutu [40] studies are more insightful into the degree to which these personality traits are correlated with job satisfaction and organizational commitment in the healthcare industry. Donnellan et al. [9] observe that the MiniIPIP Scale in the various series of studies have shown acceptable reliability and facilitate similar constructs of relationships. Mini-IPIP scale is developed from the Big Five Factors of Personality Traits have to meet the time constraints and short assessments. Michaud [41] defines that the individual's personality traits indicated by an employee who perceived the aspects of the work that determined employee's response to the situation in the organizational settings.

The concept of self-efficacy was pioneered by Albert Bandura in early 1977. It refers to one's perceived capabilities to execute the courses of action, with emphasis placed on performing skills rather than possessing skills, to achieve a given mission. Hellervik et al. have noted effectively that to achieve a mission for 
better use of various kinds of skills and acquire a belief in self-efficacy theory.

Bandura [16] further developed four major sources: inactive mastery, vicarious experience, verbal persuasion, and psychological\& affective states. An individual can fail to achieve a given mission due to over estimation of this self-efficacy. Various studies reported about the significant role played by self-efficacy as an important antecedent in the formation of entrepreneurial intentions [42].

Organizational commitment is multifaceted concept [12] [13]. Finegan [43] argues that absenteeism, job quitting, job satisfaction, job involvement, performance and relationship between supervisor and supporting staff are all relevant to the situation of the organizational commitment. Shrestha has found that demographic variables exhibit no significant differences on employees' marital status, job position, service year, education and organizational status, except ageing of the employees. This study reveals that female employees of Nepalese financial institutions have no significant difference in the level of organizational commitment between the married and single employees. However mean values of single employees are more committed to job than the married employees. Moreover, regression analysis shows organizational commitment of employees are not found significantly affected by the communication, career development, role-play working conditions, their recognition and rewards.

Agrawal [44] shows that public-sector jobs are more highly valued than the jobs of private sectors because the security of their jobs in the government sectors, even though the organizational climates in both public and private sectors are similar in nature. Nepalese employees are committed to their works but they show low levels of morale and participation. Gautam [45], Koirala [46], and Upadhyay [47] observe that the employees are dissatisfied with their jobs are common attribution to the Nepalese employees. The report of Gautam, Van Dick \& Wagner [48] show the difference in each component of antecedents of commitment leading to reduce intention to leave the organization and resulted in different outcomes for employees' affirmation with their extra-role behavior.

Luthans views that organizational commitment (OC) is an attitude that shows strong desire to remain as a loyal member in a particular organization, where the employees express their concern for consolidation of the organization. Morrow views it as a "Multidimensional Construct". Meyer and Allen [13] further indicated that commitment is characterized by suitable "Mind sets". There are affective, continuance and normative commitment that show their self-confidence and self-efficacy. The study of Muriuki \& Gachungais highly important in the field of emotional intelligence and organizational commitment. The organizational commitment is potential to predict the organizational outcomes such as performance, turnover, absenteeism, tenure, and the goals of the organization [12]. Many factors influence employees' commitment, including strong commitment to their manager's occupation, and profession as supported by the important study of Meyer \& Allen [12].

Some researchers [49]-[55] indicate the significant relationships between extraversion/introversion and organizational commitment. They show the nega- 
tive relationship between emotional stability and organizational commitment [49] [50] [51]. Kumar \& Bakhshi [49] view a significant strong relationship between openness to new experience and organizational commitment. Similarly, some studies indicate agreeableness and organizational commitment found to be significantly correlated. The review of the literature indicates that personality traits or attributes influence the decision and organizational behavior of employees. Multiple studies have found that personality factors generally influence the way of people decide and behave. A range of studies investigated the relationship between personality factors and organizational commitment of employees. A similar type of study in Indonesia among educators, teachers and lecturers by Izzati, Suhariadi, and Hadi [54] finds that shows a high amount of agreeableness shows high emotional attachment to their organization. Likewise, agreeableness and consciousness trait contribute significantly high level of affective organizational commitment. The studies of Shabahang and Amani [55] have found no gender difference between female and male principals for organizational commitment in the organization.

\section{Objectives}

1) To find the gender (Male/Female) differences in personality of the SACCOS employees.

2) To study the relationship between personality traits and self-efficacy of the SACCOS employees.

3) To study the relationship between personality traits and organizational commitment of SACCOS employees.

\section{Hypotheses}

The following three null hypotheses will be tested during this research:

1) There will be no difference in the total personality traits of male and female employees.

2) There will be no relationship between personality traits and Self-efficacy.

3) There will be no relationship between personality traits and organizational commitment.

\section{Method}

\subsection{Participants}

This study group comprises of $\mathrm{N}=260$. The total sample is collected from selected SACCOS employees of Kathmandu district dated from July, 2017 to December, 2017. See Table 1. The average age of these employees range between 18 to 75 years. The samples are collected the from the former Village Development Committee (VDC) (Now Municipality) and Kathmandu Metropolitan City.

\subsection{Measures}

The questionnaires are translated into a Nepali version and back-translated by 
two prominent professors independently and then equivalence was established [56]. The Nepali translation is further simplified by Professor M. P. Regmi. The entire analysis of data is performed with the help of SPSS Version 23.00. The Descriptive statistics, Pearson's correlation coefficient, and t-test were applied in this study (Figure 1).

\subsection{Instruments}

The Mini IPIP dimension scale has 20 items derived from 50-item IPIP-Five factor model (FFM) test. This scale is used for measuring personality traits of the person as the independent variables in terms of extraversion, agreeableness, conscientiousness, emotional stability, and intellect developed by Donnellan, Oswald, Baird \& Lucas [9]. The researchers have used a 5-point Likert-type scale ranging from (1 strongly disagreed to 5 strongly agreed) with a neutral midpoint at 3 (neither disagree nor agree). The scores for the individual items from each scale are summated to find the total scores for each of the five constructs (FFM). The scale has Five factor model (FFM) or Constructs. The Cronbach's Alphas of

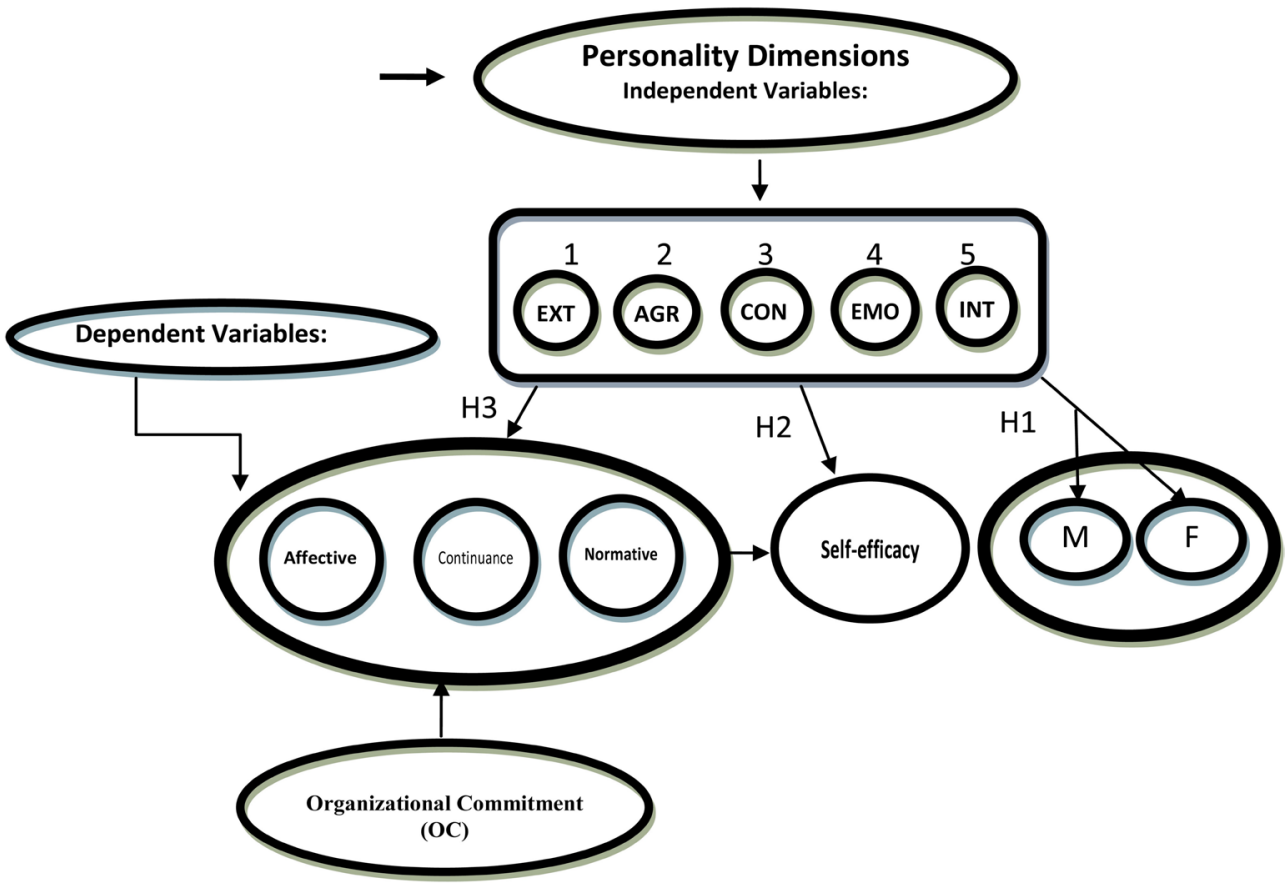

(Theoretical model developed by Prof. Dr. M.P. Regmi \& D.M. Basnet's doctoral research proposal has presented at Pacific Academy of Higher Education and Research University, Rajasthan, Udaipur, India on November 11, 2016).

Figure 1. Theoretical framework of this study.

Table 1. Sample Structure $(\mathrm{N}=260)$.

\begin{tabular}{ccc}
\hline Total Employees & Males & Females \\
\hline 260 & 127 & 133 \\
Percentage & $48.85 \%$ & $51.15 \%$ \\
\hline
\end{tabular}


the five constructs are $0.77,0.70,0.69,0.68$, and 0.65 sequentially.

The construct of self-efficacy scale is introduced by Bandura as Social-Cognitive Theory [15] [16] [17]. Later Ralf Schwarzer \& Matthias Jerusalem revised the scale in 2000 as Generally Perceived Self-efficacy Scale and unidimensional. It consists of Ten-item version with 4 Point-Likert type scales. Its high scores reflected higher levels of self-efficacy and aimed to deal efficiently with a variety of stressful situation. The scale is translated into 33 languages and tested in 23 countries and widely used in numerous research projects. The Cronbach's alphas ranged from 0.76 to 0.90 with the majority in the high $0.80 \mathrm{~s}$.

This study uses the organizational commitment questionnaire developed by Meyer and Allen [13]. It consists of 24 items and 5 Point-Likert type scale. It has three categories: affective, continuance and normative commitment. In this study the high scores reflect higher levels of organizational commitment of the employees. Researchers have deleted 3 items from normative commitment, so the total functional items are 21 only. The reported Cronbach's alphas for the three subscales were $0.87,0.75$, and 0.79 respectively [13].

\subsection{Procedure}

First, the researcher requested the head of the SACCOS office with the written request letter of researcher along with the recommendation letter of Division Co-operative office, Kathmandu district, after taking the consent from employees, the researcher requested the employees to be seated in a room of the SACCOS and distributed the questionnaires package to each subject and they were instructed by the researchers before filling-up the questionnaires. They filled the questionnaire package within 15 to 20 minutes. In the similar procedure, each SACCOS office was visited by the researcher/s for data collection. Entire data collection took approximately Five-months time.

\subsection{Data Analysis}

In the trait of extraversion, the span of mean scores range from highest in the item No. 1 and lowest in the item No. 16. Similarly, agreeableness trait has the highest mean score in the item No. 12 and lowest value in the item No. 13. In case of conscientiousness trait, the mean score is highest in the item no. 18 and then the mean score of lowest item No. 13. Emotional stability trait in item No. 9 is the highest mean score and lowest mean score is found in 14 item. Similarly, the trait of intellect shows the highest mean score in item No. 20 and lowest mean score falls in item No. 15 . The agreeableness trait has highest reliability $(\mathrm{r}=$ $30.9)$ and the lowest reliability exhibited by extraversion trait $(r=0.06)$. Furthermore, the above table shows 14 negative skewed scores value 14 and kurtosis is found 16 in Mini-IPIP FFM personality. This proves the lack of normality in the MINI-IPIP Scale (See Table 2).

Table 3(a) exhibits, the Mean ( $M=31.68)$, SD (31.68) scores and Cronbach's Alpha (0.818) of Self-efficacy, respectively. 
Table 2. Statistics for the Mini-IPIP-FFM Personality Scale.

\begin{tabular}{|c|c|c|c|c|c|c|}
\hline Item/Symbol & $\mathrm{N}$ & Mean & $\begin{array}{c}\text { Std. } \\
\text { Deviation }\end{array}$ & Skewness & Kurtosis & $\begin{array}{c}\text { Cronbach } \\
\text { Alpha }\end{array}$ \\
\hline 1 (EMO) & 260 & 3.92 & 1.163 & -1.126 & 0.604 & \\
\hline 2 (AGR) & 260 & 4.39 & 0.979 & -1.925 & 3.483 & \\
\hline $3(\mathrm{CON})$ & 260 & 3.16 & 1.593 & -0.256 & -1.525 & \\
\hline 4 (EMO) & 260 & 3.31 & 1.305 & -0.523 & -0.873 & \\
\hline $5(\mathrm{INT})$ & 260 & 3.18 & 1.385 & -0.238 & -1.198 & \\
\hline $5(\mathrm{EMO})$ & 260 & 2.64 & 1.431 & 0.376 & -1.211 & \\
\hline 7 (AGR) & 260 & 3.95 & 1.308 & -0.967 & -0.367 & \\
\hline $8(\mathrm{CON})$ & 260 & 3.58 & 1.430 & -0.464 & -1.290 & \\
\hline $9(\mathrm{EMO})$ & 260 & 3.36 & 1.422 & -0.188 & -1.410 & \\
\hline 10 (INT) & 260 & 3.62 & 1.329 & -0.519 & -0.986 & \\
\hline 11 (EMO) & 260 & 3.71 & 1.457 & -0.772 & -0.854 & \\
\hline 12 (AGR) & 260 & 4.58 & 0.890 & -2.644 & 7.015 & \\
\hline $13(\mathrm{CON})$ & 260 & 4.12 & 1.225 & -1.328 & 0.698 & \\
\hline 14 (EMO) & 260 & 2.66 & 1.452 & 0.156 & -1.444 & \\
\hline 15 (INT) & 260 & 2.21 & 1.260 & 0.749 & -0.557 & \\
\hline $16(\mathrm{EMO})$ & 260 & 2.13 & 1.359 & 0.907 & -0.481 & \\
\hline 17 (AGR) & 260 & 2.78 & 1.517 & 0.243 & -1.446 & \\
\hline $18(\mathrm{CON})$ & 260 & 3.99 & 1.472 & -1.079 & -0.454 & \\
\hline 19 (EMO) & 260 & 2.73 & 1.381 & 0.315 & -1.200 & \\
\hline 20 (INT) & 260 & 3.66 & 1.336 & -0.576 & -0.948 & \\
\hline \multicolumn{7}{|l|}{ Total Scores: } \\
\hline Extraversion (EXT) & & 12.4 & 5.41 & & & $6 \%$ \\
\hline Agreeableness(AGR) & & 15.7 & 4.694 & & & $30.9 \%$ \\
\hline Conscientiousness(CON) & & 14.85 & 5.72 & & & $29.9 \%$ \\
\hline Emotional Stability(EMO) & & 12.06 & 5.56 & & & $23.2 \%$ \\
\hline Intellect (INT) & & 12.67 & 5.31 & & & $12.1 \%$ \\
\hline
\end{tabular}

Table 3(b) exhibits, the Means (30.26), (25.32), (18.43), SD (9.004), (10.134), (5.769) scores and Cronbach's Alpha (0.644), (0.737), (0.549) of affective, continuance and normative commitment respectively.

\section{Hypothesis Testing-1}

Table 4 exhibits the emotional stability trait of the Mini-IPIP dimension, females' Mean $(\mathrm{M}=11.5354)$ \& males' Mean $(\mathrm{M}=12.5489)$ score is 1.0135 higher (or significantly different) (see Table 4). It proves that female employees have higher emotional instability than the male employees of SACCOS. Magnus et al. claimed that the neurotic employees experience more negative life situations than the other individuals. Similarly, neurotics experience higher anxiety while facing a new work environment that may lead to harsher experiences. The above findings seem to be affected by the female employees specifically to the comparison of the male employees. 
Table 3. (a) Statistics for the Self-efficacy Scale. (b) Statistics for Affective, Continuance and Normative Commitment Scales.

(a)

\begin{tabular}{ccccc}
\hline Scale & N & Mean & $\begin{array}{c}\text { Standard } \\
\text { Deviation (SD) }\end{array}$ & $\begin{array}{c}\text { Cronbach's } \\
\text { Alpha }\end{array}$ \\
\hline Self-efficacy & 260 & 31.68 & 8.598 & 0.818 \\
\hline Scales & N & Mean & $\begin{array}{c}\text { Standard Deviation } \\
\text { (SD) }\end{array}$ & $\begin{array}{c}\text { Cronbach's } \\
\text { Alpha }\end{array}$ \\
\hline Organizational & & & & \\
1) Affective & \multirow{2}{*}{ 260 } & 30.26 & 9.004 & 0.644 \\
2) Continuance & & 25.32 & 10.134 & 0.737 \\
3) Normative & & 18.43 & 5.769 & 0.549 \\
\hline
\end{tabular}

Table 4. T-test, gender differences in the total personality traits.

\begin{tabular}{|c|c|c|c|c|c|c|c|}
\hline \multicolumn{6}{|c|}{ Group Statistics(Male/Female) } & \multirow[b]{2}{*}{ Effect } & \multirow[b]{2}{*}{ Decision } \\
\hline Personality Trait & Gender & $\mathbf{N}$ & Mean & $\begin{array}{c}\text { Std. } \\
\text { Deviation }\end{array}$ & $\begin{array}{l}\text { Std. Error of } \\
\text { Mean(SEM) }\end{array}$ & & \\
\hline \multirow{2}{*}{ Extraversion } & Male & 127 & 12.3701 & 2.66608 & 0.23658 & Lower & \\
\hline & Female & 133 & 12.4211 & 2.88993 & 0.25059 & Higher & \\
\hline \multirow{2}{*}{ Agreeableness } & Male & 127 & 15.748 & 2.84513 & 0.25246 & Higher & \\
\hline & Female & 133 & 15.6767 & 2.64446 & 0.2293 & Lower & \\
\hline \multirow{2}{*}{ Conscientiousness } & Male & 127 & 14.9449 & 3.46481 & 0.30745 & Higher & \\
\hline & Female & 133 & 14.7444 & 3.03927 & 0.26354 & Lower & \\
\hline \multirow{2}{*}{$\begin{array}{l}\text { Emotional } \\
\text { stability }\end{array}$} & Male & 127 & 11.5354 & 3.03889 & 0.26966 & Higher & $1.0135^{\star}$ Sig. \\
\hline & Female & 133 & 12.5489 & 3.00622 & 0.26067 & Lower & Dinterente \\
\hline \multirow{2}{*}{ Intellect } & Male & 127 & 12.6535 & 2.78994 & 0.24757 & Lower & \\
\hline & Female & 133 & 12.6842 & 2.81061 & 0.24371 & Higher & \\
\hline
\end{tabular}

In the remaining other four personality dimension (extraversion, agreeableness, conscientiousness and intellect), Mean scores are nearly the same and statistically remain significant between male and female employees.

\section{Hypothesis Testing-2}

Table 5 shows that the significant high correlations among four personality traits: The self-efficacy value correlates with four personality traits: agreeableness $(r=0.297)$, conscientiousness $(r=0.218)$, emotional stability is negatively $(r=$ $-0.199)$, and intellect $(r=0.274)$. Thus, the extraversion $(r=0.061)$ trait has no significant correlation with self-efficacy. This proves the four traits have significant positive relationship with self-efficacy. In conclusion, the trait of extraversion has no any relationship with self-efficacy. Talkativeness, energetic, and emotionally expressive are the contents of the extraversion trait, but these behaviors do not correlate with self-efficacy of SACCOS employees. It concludes that self-efficacy has no relation with extraversion trait in the area of SACCO's em- 
ployees.

Table 6 exhibits that agreeableness trait highly correlates with conscientiousness $(r=0.303)$, and intellect $(r=0.202)$. Similarly, agreeableness negatively correlates with emotional stability $(r=-0.160)$. The conscientiousness highly correlates with the agreeableness $(r=0.303)$ and correlates with intellect $(r=$ $0.132)$ and correlates with the conscientiousness $(r=0.132)$. The extraversion trait has no any relation to the rest of the personality traits.

\section{Hypotheses Testing-3}

Table 7 exhibits that there is no significant correlation between extraversion trait and all the three variables (affective, continuance, and normative) of the organizational commitment. The extraversion trait is related to talkativeness, full of energy and emotionally expressive [2]. The analysis proves that employees

Table 5. Correlation among the personality dimensions and self-efficacy.

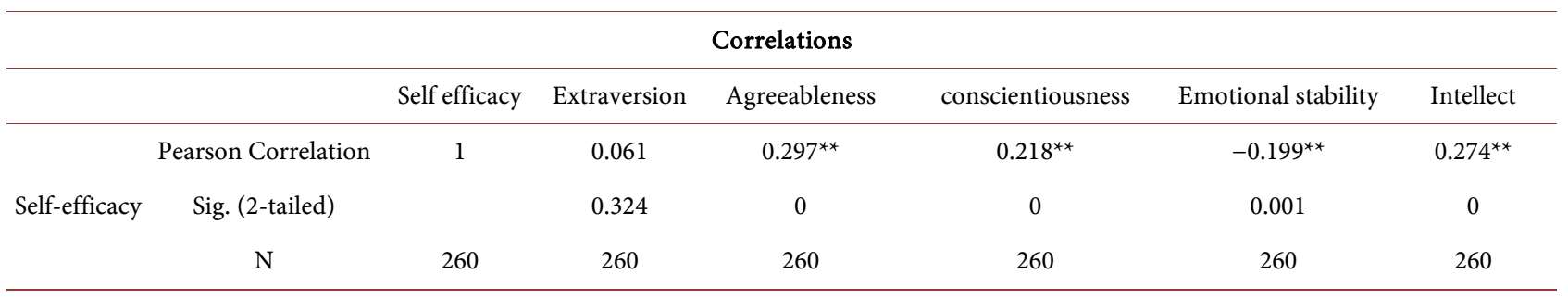

${ }^{* *}$ Correlation is significant at the 0.01 level (2-tailed). ${ }^{*}$ Correlation is significant at the 0.05 level (2-tailed).

Table 6. The Inter-correlations within the five personality traits.

\begin{tabular}{|c|c|c|c|c|c|c|c|}
\hline \multicolumn{8}{|c|}{ Correlations } \\
\hline & & Self-efficacy & Extraversion & Agreeableness & Conscientiousness & $\begin{array}{c}\text { Emotional } \\
\text { stability }\end{array}$ & Intellect \\
\hline \multirow{3}{*}{ Extraversion } & Pearson Correlation & 0.061 & 1 & 0.111 & -0.082 & -0.047 & 0.033 \\
\hline & Sig. (2-tailed) & 0.324 & & 0.073 & 0.187 & 0.454 & 0.598 \\
\hline & $\mathrm{N}$ & 260 & 260 & 260 & 260 & 260 & 260 \\
\hline \multirow{3}{*}{ Agreeableness } & Pearson Correlation & $0.297^{\star *}$ & 0.111 & 1 & $0.303^{\star *}$ & $-0.160^{\star *}$ & $0.202^{\star *}$ \\
\hline & Sig. (2-tailed) & 0 & 0.073 & & 0 & 0.01 & 0.001 \\
\hline & $\mathrm{N}$ & 260 & 260 & 260 & 260 & 260 & 260 \\
\hline \multirow{3}{*}{ Conscientiousness } & Pearson Correlation & $0.218^{\star *}$ & -0.082 & $0.303^{\star \star}$ & 1 & -0.076 & $0.132^{\star}$ \\
\hline & Sig. (2-tailed) & 0 & 0.187 & 0 & & 0.219 & 0.033 \\
\hline & $\mathrm{N}$ & 260 & 260 & 260 & 260 & 260 & 260 \\
\hline \multirow{3}{*}{ Emotional stability } & Pearson Correlation & $-0.199^{* *}$ & -0.047 & $-0.160^{\star *}$ & -0.076 & 1 & -0.081 \\
\hline & Sig. (2-tailed) & 0.001 & 0.454 & 0.01 & 0.219 & & 0.193 \\
\hline & $\mathrm{N}$ & 260 & 260 & 260 & 260 & 260 & 260 \\
\hline \multirow{3}{*}{ Intellect } & Pearson Correlation & $0.274^{\star \star}$ & 0.033 & $0.202^{\star *}$ & $0.132^{\star}$ & -0.081 & 1 \\
\hline & Sig. (2-tailed) & 0 & 0.598 & 0.001 & 0.033 & 0.193 & \\
\hline & $\mathrm{N}$ & 260 & 260 & 260 & 260 & 260 & 260 \\
\hline
\end{tabular}

${ }^{* *}$ Correlation is significant at the 0.01 level (2-tailed). ${ }^{\star}$ Correlation is significant at the 0.05 level (2-tailed). 
Table 7. The Inter-correlation of Personality Traits and Organizational Commitment.

\begin{tabular}{|c|c|c|c|c|c|c|c|c|c|}
\hline \multicolumn{10}{|c|}{ Correlations } \\
\hline \multicolumn{2}{|c|}{ Personality Traits } & \multirow{2}{*}{$\begin{array}{c}\begin{array}{c}\text { Extra_ } \\
\text { version }\end{array} \\
1\end{array}$} & \multirow{2}{*}{$\begin{array}{c}\text { Agreeableness } \\
0.111\end{array}$} & \multirow{2}{*}{$\begin{array}{c}\begin{array}{c}\text { conscienti } \\
\text { ousness }\end{array} \\
-0.082\end{array}$} & \multirow{2}{*}{$\begin{array}{c}\begin{array}{c}\text { Emotional } \\
\text { stability }\end{array} \\
-0.047\end{array}$} & \multirow{2}{*}{$\begin{array}{c}\text { Intellect } \\
0.033\end{array}$} & \multirow{2}{*}{$\begin{array}{c}\begin{array}{c}\text { Affective } \\
\text { commitment }\end{array} \\
0.091\end{array}$} & \multirow{2}{*}{$\begin{array}{c}\text { Continuance } \\
-0.022\end{array}$} & \multirow{2}{*}{$\begin{array}{c}\text { Normative } \\
0.026\end{array}$} \\
\hline & Pearson Correlation & & & & & & & & \\
\hline \multirow[t]{3}{*}{ Extraversion } & Sig. (2-tailed) & & 0.073 & 0.187 & 0.454 & 0.598 & 0.145 & 0.722 & 0.676 \\
\hline & $\mathrm{N}$ & 260 & 260 & 260 & 260 & 260 & 260 & 260 & 260 \\
\hline & Pearson Correlation & 0.111 & 1 & $0.303^{* *}$ & $-0.160^{\star *}$ & $0.202^{* *}$ & $0.309^{* *}$ & 0.089 & $0.179^{* *}$ \\
\hline \multirow[t]{3}{*}{ Agreeableness } & Sig. (2-tailed) & 0.073 & & 0 & 0.01 & 0.001 & 0 & 0.153 & 0.004 \\
\hline & $\mathrm{N}$ & 260 & 260 & 260 & 260 & 260 & 260 & 260 & 260 \\
\hline & Pearson Correlation & -0.082 & $0.303^{* *}$ & 1 & -0.076 & $0.132^{*}$ & $0.166^{\star *}$ & -0.043 & $0.213^{* *}$ \\
\hline \multirow[t]{3}{*}{ Conscientiousness } & Sig. (2-tailed) & 0.187 & 0 & & 0.219 & 0.033 & 0.007 & 0.486 & 0.001 \\
\hline & $\mathrm{N}$ & 260 & 260 & 260 & 260 & 260 & 260 & 260 & 260 \\
\hline & Pearson Correlation & -0.047 & $-0.160^{* *}$ & -0.076 & 1 & -0.081 & $-0.143^{\star}$ & 0.06 & -0.119 \\
\hline \multirow[t]{3}{*}{$\begin{array}{l}\text { Emotional } \\
\text { stability }\end{array}$} & Sig. (2-tailed) & 0.454 & 0.01 & 0.219 & & 0.193 & 0.021 & 0.334 & 0.055 \\
\hline & $\mathrm{N}$ & 260 & 260 & 260 & 260 & 260 & 260 & 260 & 260 \\
\hline & Pearson Correlation & 0.033 & $0.202^{* *}$ & $0.132^{*}$ & -0.081 & 1 & $0.261^{* *}$ & 0.004 & 0.088 \\
\hline \multirow[t]{3}{*}{ Intellect } & Sig. (2-tailed) & 0.598 & 0.001 & 0.033 & 0.193 & & 0 & 0.945 & 0.158 \\
\hline & $\mathrm{N}$ & 260 & 260 & 260 & 260 & 260 & 260 & 260 & 260 \\
\hline & Pearson Correlation & 0.091 & $0.309^{* *}$ & $0.166^{\star *}$ & $-0.143^{\star}$ & $0.261^{* *}$ & 1 & $0.331^{* *}$ & $0.523^{* *}$ \\
\hline \multirow[t]{3}{*}{$\begin{array}{c}\text { Affective } \\
\text { commitment }\end{array}$} & Sig. (2-tailed) & 0.145 & 0 & 0.007 & 0.021 & 0 & & 0 & 0 \\
\hline & $\mathrm{N}$ & 260 & 260 & 260 & 260 & 260 & 260 & 260 & 260 \\
\hline & Pearson Correlation & -0.022 & 0.089 & -0.043 & 0.06 & 0.004 & $0.331^{\star *}$ & 1 & $0.245^{* *}$ \\
\hline \multirow[t]{3}{*}{ Continuance } & Sig. (2-tailed) & 0.722 & 0.153 & 0.486 & 0.334 & 0.945 & 0 & & 0 \\
\hline & $\mathrm{N}$ & 260 & 260 & 260 & 260 & 260 & 260 & 260 & 260 \\
\hline & Pearson Correlation & 0.026 & $0.179^{* *}$ & $0.213^{* *}$ & -0.119 & 0.088 & $0.523^{\star *}$ & $0.245^{\star \star}$ & 1 \\
\hline \multirow[t]{2}{*}{ Normative } & Sig. (2-tailed) & 0.676 & 0.004 & 0.001 & 0.055 & 0.158 & 0 & 0 & \\
\hline & $\mathrm{N}$ & 260 & 260 & 260 & 260 & 260 & 260 & 260 & 260 \\
\hline
\end{tabular}

${ }^{* *}$ Correlation is significant at the 0.01 level (2-tailed). ${ }^{*}$ Correlation is significant at the 0.05 level (2-tailed).

who scored low in the extraversion have poor degree of social networks and socially inactive. The individual who scores high in extraversion shows low continuance commitment. This proves that there is a negative relationship between extraversion and continuance commitment. The agreeableness trait highly correlates $(r=0.309)$ with the affective commitment and significantly correlates with the normative $(r=0.179)$ commitment. But the agreeableness trait shows no relationship with the continuance commitment (Erdheim et al., 2006) prove that agreeableness trait has no relationship with the continuance commitment $(r$ 
$=0.02, \mathrm{p}>0.05)$ in a sample of American employees.

Similarly, the conscientiousness trait highly correlates $(r=0.166)$ with the affective commitment and correlates with normative commitment $(r=0.213)$. It does not have relationship with continuance commitment $(r=-0.043)$. The empirical research, [57] [58] shows the positive correlation between conscientiousness and affective commitment. The increasing character of the conscientiousness trait leads to the degree of employees' involvement and attachments affectively to the organization. A regression analysis of the Indonesian School teachers samples by Izzati, Suhariadi and Hadi [54] have shown that there is a significant relationship between agreeableness $(r=0.000, p>0.05) \&$ conscientiousness $(\mathrm{r}=0.000, \mathrm{p}>0.05)$ with affective commitment.

The emotional stability trait correlates negatively $(\mathrm{r}=-0.143)$ with the affective commitment. The employees scoring high in emotional stability trait shows higher continuance commitment. This research tries to prove $(r=0.06)$ in comparison to normative commitment $(r=-0.11)$. Positive relation between emotional stability and continuance is expected. Similarly, intellect trait highly correlates $(\mathrm{r}=0.261, \mathrm{p}<0.01)$ with the affective commitment. This result of an association between openness and affective commitment is consistent with the similar result as shown by Erdheim et al. [27]. The previous researches are found to be similar, and that trait of the intellect has positive relationship with the affective commitment which lowers down the turnover behavior of the employees.

The F-ratio 3.997 which is significant at 0.05 levels (2 tail test). Please see Table 8 .

Table 8. t-test: (Independent Sample Test).

Independent Samples Test

\begin{tabular}{|c|c|c|c|c|c|c|c|c|c|c|}
\hline \multirow{3}{*}{\multicolumn{2}{|c|}{ Personality Traits }} & \multicolumn{3}{|c|}{$\begin{array}{l}\text { Levene's Test for } \\
\text { Equality of Variances }\end{array}$} & \multicolumn{4}{|c|}{ t-test for Equality of Means } & & \\
\hline & & \multirow[t]{2}{*}{$\mathrm{F}$} & \multirow[t]{2}{*}{ Sig. } & \multirow[t]{2}{*}{$\mathrm{t}$} & \multirow[t]{2}{*}{ Df } & \multirow[t]{2}{*}{$\begin{array}{c}\text { Sig. } \\
\text { (2-tailed) }\end{array}$} & \multirow[t]{2}{*}{$\begin{array}{c}\text { Mean } \\
\text { Difference }\end{array}$} & \multirow[t]{2}{*}{$\begin{array}{l}\text { Std. Error } \\
\text { Difference }\end{array}$} & \multicolumn{2}{|c|}{$\begin{array}{l}\text { 95\% Confidence } \\
\text { Interval of the } \\
\text { Difference }\end{array}$} \\
\hline & & & & & & & & & Lower & Upper \\
\hline \multirow{2}{*}{ Extraversion } & Equal variances assumed & 0.948 & 0.331 & -0.15 & 258 & 0.883 & -0.05097 & 0.34526 & -0.73087 & 0.62892 \\
\hline & Equal variances not assumed & & & -0.15 & 257.7 & 0.883 & -0.05097 & 0.34462 & -0.7296 & 0.62766 \\
\hline \multirow{2}{*}{ Agreeableness } & Equal variances assumed & 1.844 & 0.176 & 0.21 & 258 & 0.834 & 0.07134 & 0.34048 & -0.59913 & 0.74181 \\
\hline & Equal variances not assumed & & & 0.209 & 254.39 & 0.834 & 0.07134 & 0.34105 & -0.60031 & 0.74299 \\
\hline \multirow{2}{*}{ Conscientiousness } & Equal variances assumed & 3.997 & 0.047 & 0.497 & 258 & 0.62 & 0.20052 & 0.40372 & -0.59449 & 0.99553 \\
\hline & Equal variances not assumed & & & 0.495 & 250.23 & 0.621 & 0.20052 & 0.40494 & -0.59701 & 0.99805 \\
\hline \multirow{2}{*}{ Emotional stability } & Equal variances assumed & 0.041 & 0.839 & -2.7 & 258 & 0.007 & -1.01344 & 0.37496 & -1.75181 & -0.27507 \\
\hline & Equal variances not assumed & & & -2.7 & 257.16 & 0.007 & -1.01344 & 0.37505 & -1.75201 & -0.27487 \\
\hline \multirow{2}{*}{ Intellect } & Equal variances assumed & 0.028 & 0.868 & -0.09 & 258 & 0.93 & -0.03067 & 0.34746 & -0.71488 & 0.65354 \\
\hline & Equal variances not assumed & & & -0.09 & 257.61 & 0.93 & -0.03067 & 0.3474 & -0.71477 & 0.65343 \\
\hline
\end{tabular}




\section{Further Statistical Analysis}

\section{Fit-Statistics for the Mini-IPIP Model and Organizational Commitment:}

The alphas in the normative commitment and all the IPIP subscales are indeed low and the researchers have to run an alternative method of checking the scaled reliability called the Tau Equivalent. The Cronbach's alpha has been criticized by some researchers as being too conservative-that is, as showing low reliability where the reliability is actually higher. The Tau Equivalent is a more robust method based on Structural Equation Modeling-researchers run these analyze on the AMOS software. It is found that with the exception of extraversion, the rest of the scales have from excellent to acceptable reliability. Researchers use the following fit indices:

Chi square: This needs to be as close to zero and non-significant CFI, IFI, and NFI: ideally these need to be 0.95 or over, but 0.9 or over is acceptable by most researches.

The Root Mean Square Error of Approximation (RMSEA): Ideally this needs to be below 0.06 but 0.08 or below is acceptable by most researches.

The findings are:

For normative commitment, excellent reliability: Chi sq $=17.97, \mathrm{p}=0.598, \mathrm{df}$ = 20; The CFI (Comparative Fit Index): 1, IFI: 1, NFI: 1, RMSEA 0.00 .

For extraversion, poor reliability: Chi $\mathrm{sq}=4.59, \mathrm{p}=0.101, \mathrm{df}=2$; $\mathrm{CFI}=0.5$, $\mathrm{IFI}=0.8, \mathrm{NFI}=0.69, \mathrm{RMSEA}=0.098$.

For agreeableness, good reliability: $\mathrm{Chi} s \mathrm{sq}=2.68, \mathrm{p}=0.261, \mathrm{df}=2$; $\mathrm{CFI}=0.94$, $\mathrm{IFI}=0.96, \mathrm{NFI}=0.87, \mathrm{RMSEA}=0.05$.

For conscientiousness, acceptable reliability: Chi $s q=3.28, \mathrm{p}=0.193, \mathrm{df}=2$; $\mathrm{CFI}=0.94, \mathrm{IFI}=0.96, \mathrm{NFI}=0.89, \mathrm{RMSEA}=0.07$.

For emotional stability, marginally acceptable reliability: Chi sq $=1.91, \mathrm{p}=$ $0.166, \mathrm{df}=1 ; \mathrm{CFI}=0.76, \mathrm{IFI}=0.93, \mathrm{NFI}=0.86, \mathrm{RMSEA}=0.08$.

For intellect, very good reliability: Chi $\mathrm{sq}=1.876, \mathrm{p}=0.391, \mathrm{df}=2$; $\mathrm{CFI}=1$, $\mathrm{IFI}=1, \mathrm{NFI}=0.87$, RMSEA $=0.00$.

The problems in scale reliability may come from various sources. For example, some participants may not have understood some of the items, or there may be some issues in translating the items and/or cultural differences in interpreting the items. Researchers would not be surprised if there were cultural differences given that openness to others, socialization, and expressiveness captured by "extroversion" notions and understood very differently across cultures. Perhaps scholars need to look at reliability of the same instrument in other related countries of South East Asia. Now the researchers have found all 6 figures and outputs by the use of AMOS-21 version. These figures are sequentially presented in the following pages.

Paths Analysis for Organizational Commitment and Personality Traits (Figures 2-7).

\section{Organizational Commitment: \\ Personality Traits (Mini-IPIP Model):}




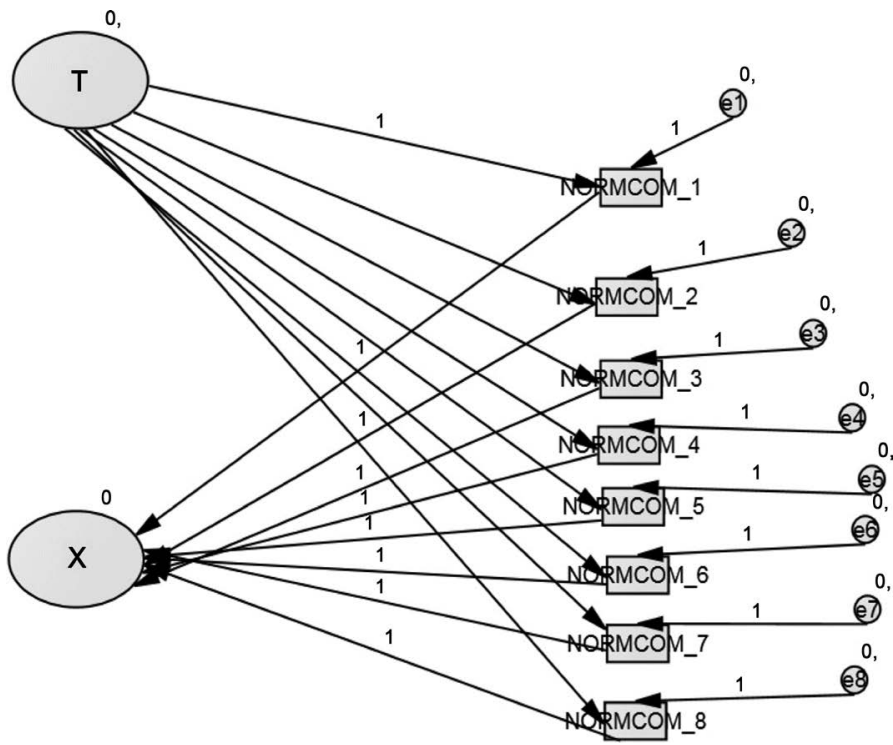

Figure 2. Model diagram for normative commitment.

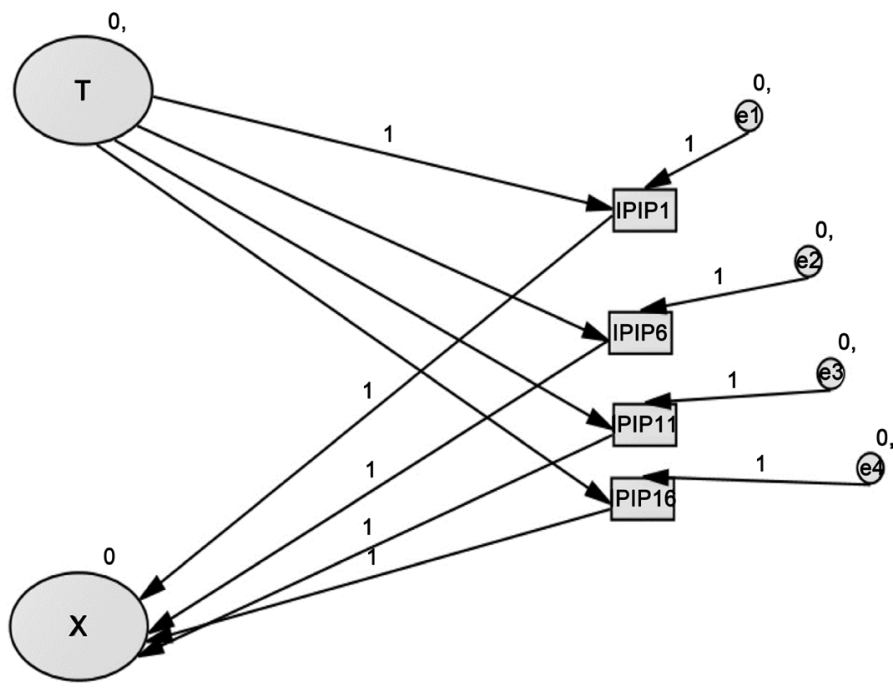

Figure 3. Model diagram for extraversion.

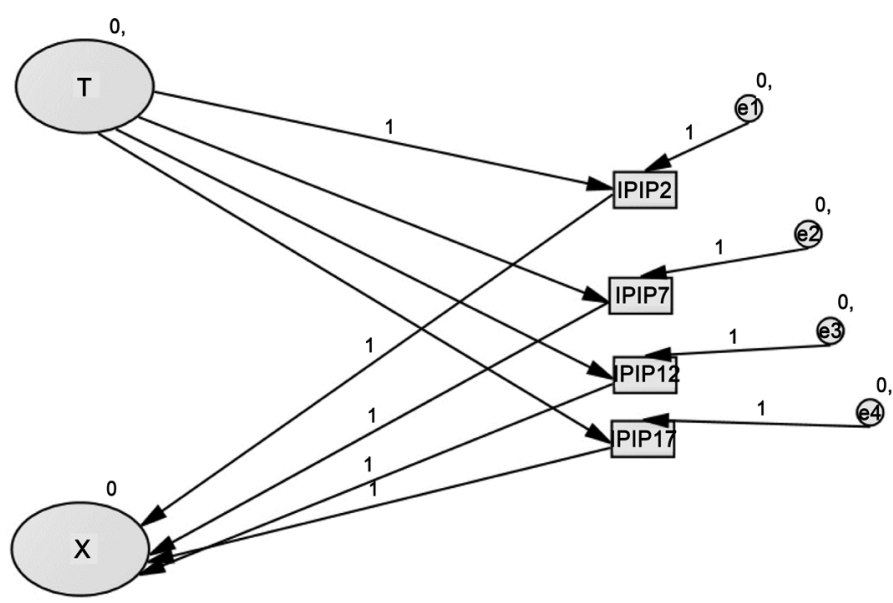

Figure 4. Model diagram for agreeableness. 


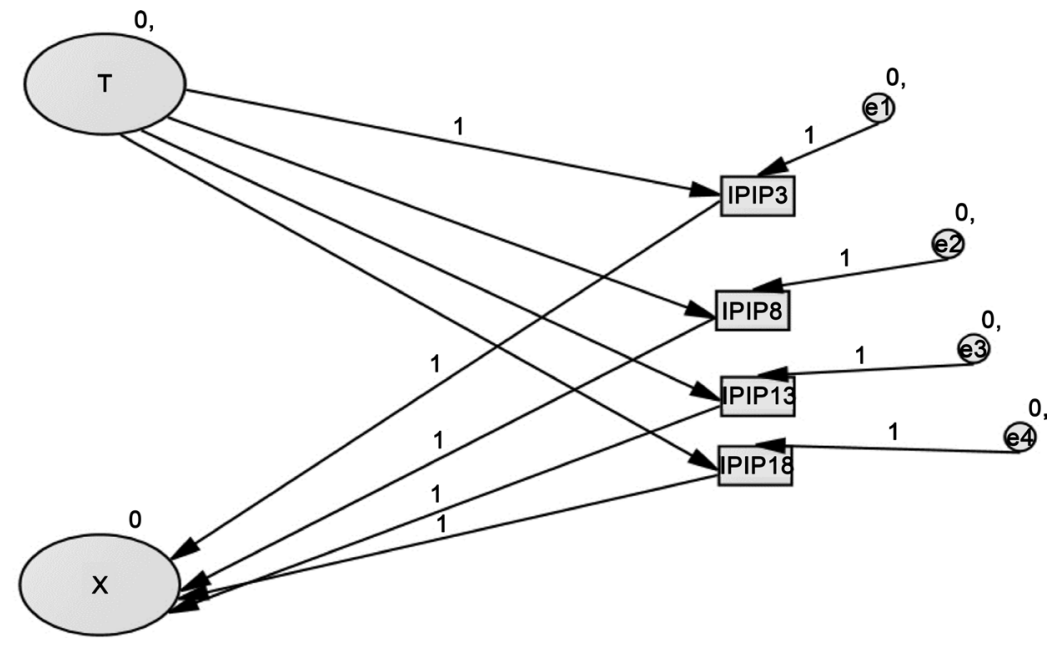

Figure 5. Model diagram for conscientiousness.

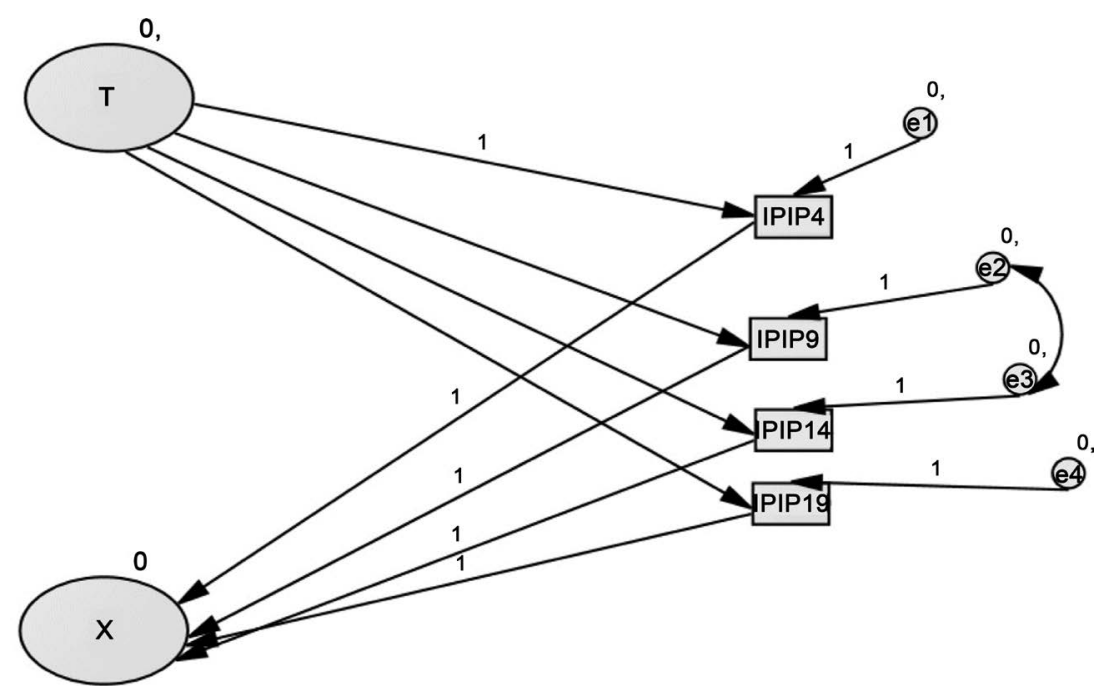

Figure 6. Model diagram for emotional stability.

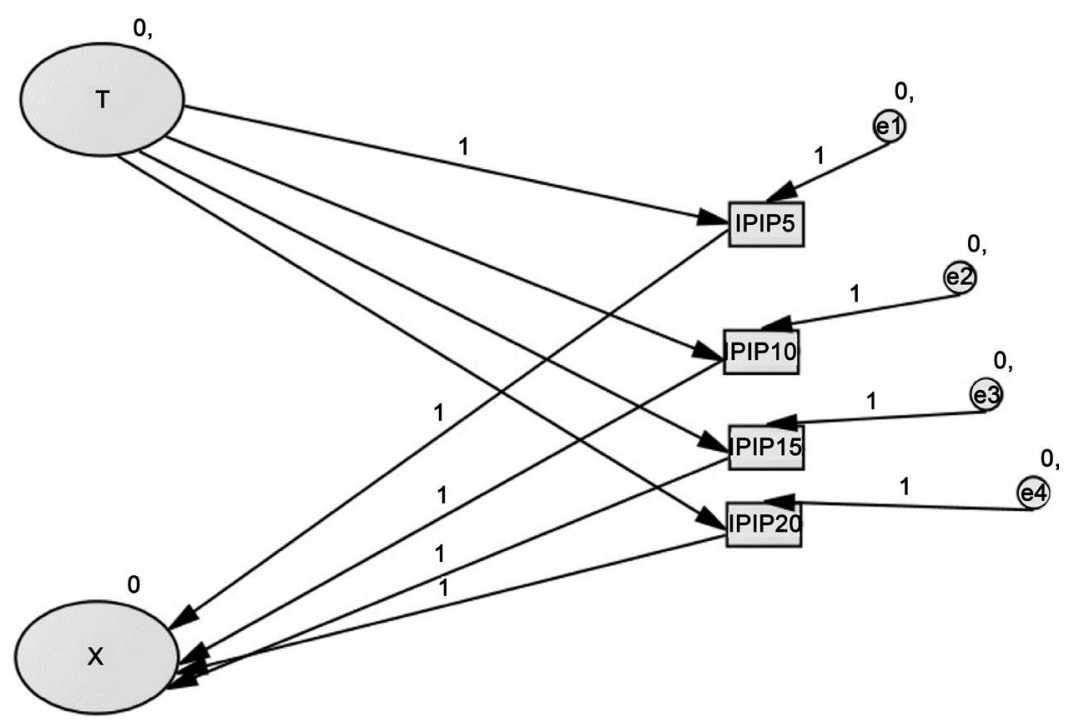

Figure 7. Model diagram for intellect. 


\section{Result and Discussion}

The female employees Mean score 1.0135 is higher and significantly different from male employees. The three personality traits (agreeableness, conscientiousness, and intellect) highly correlate with self-efficacy, but the emotional stability trait negatively correlates with self-efficacy. The trait of agreeableness highly correlates with affective and normative commitment. The trait of conscientiousness highly correlates with affective and normative commitment. This research also support researches by Erdheim, et al. [27], Matzler \& Renzl [58] and Lzzati, U. A, Suhariadi, F. and Hadi, C. [54] have found that the positive correlation between conscientiousness and affective commitment.

However, the emotional stability trait negatively correlates with affective commitment. Likewise, the intellect trait highly correlates with affective commitment. The continuance commitment of SACCOS's female employees is due to their nearness of dwelling and their emotional instability is little higher than the male employees. When the employees found highly correlated with affective commitment that results employee's turnover rate will be low in the organization.

\section{Conclusions}

It can be concluded that three personality traits (agreeableness, conscientiousness, and intellect) are correlated positively with self-efficacy. The emotional stability trait is significant difference between male and female employees and level of emotional stability is higher than that of male employees.

In the result, affective and normative commitments have simply negative correlation with emotional stability. The affective and normative commitment is highly correlated with agreeableness. The normative and affective commitment highly correlates with conscientiousness. Likewise, the affective commitment highly correlates with the intellect.

Aryal \& Panta [59] reported in their study that the Nepalese Co-operative members have inadequate knowledge about financial literacy and depend only on internal sources of information while making the plans and policies by their co-operative employees and adopting the traditional decision making process.

\section{Recommendations and Suggestions}

Male employees should have positive regards to the female employees (colleagues). The Saving and Credit Co-operative employees tend to have strong desire to shift their existing job into alternative job. The SACCOS employees ought to develop cooperation in the work setting to improve working environment, and to build-up the constructive relationship with workplace. The SACCOS employees exhibited less efficiency in their work. It is also highly recommended that the efficiency of the future studies should relate to personality traits, organizational commitment and self-efficacy. It can be conducted in the different natures of the Co-operatives in the country and World. The government of 
Nepal has given priority since restoration of democracy since 1990 to develop the overall socio-economic through Co-operative sectors. The Co-operative should consider researches, training \& development to the human resources and Co-operative members through Education Sub-committee of the respective nature of Co-operatives. These Co-operative sectors seem to be helpful to develop sustainable economic growth in the country in micro level by proper utilizing human resources and members of the Co-operatives. To some extent, the Co-operative sector should consider their employees' benefits like working in the Nepalese commercial \&development banks and finance companies to increase their personality, organization citizenship behavior (OCB) and efficacy. In the present scenario, the majority of SACCOS are transacting saving and credit and locating in prime area of the locality and consumer market place to serve their members. The Nepalese Co-operative Act, 2017 has given priority for inter-Co-operative transactions among the Co-operatives. Basnet, Birla, and Regmi [62] defined that the graduate level employees of SACCOS' self-efficacy shows negative correlation with continuance commitment. Therefore, graduate level employees are not interested to use their knowledge, skills, and interest to accomplish their assign tasks and responsibilities. Basnet et al. [62] prove that the Kathmandu Metropolitan City (KMC), Municipality and Village Development Committee (VDC) SACCOS employees' self-efficacy levels remain same.

\section{Limitations}

This survey research is conducted in limited research area of Kathmandu district only. There have been very few researches conducted in the area of commitment, personality traits and self-efficacy in Nepal. However, no study has been found in analyzing the relationship among the personality traits, self-efficacy and organizational commitment in the Nepalese Co-operatives employees. In this respect, this study will be helpful for shedding a light in the field for further studies to the related areas of human resources management. Recently theory testing researches are coming up [60] [61]. These types of researches are not facing by the respondents in the population areas. This may cause to answer properly in the standardize scales.

The researchers have collected the samples for the study of the doctoral research.

\section{Implications}

There are several practical implications for reducing turnover, job search behaviors, increasing commitment to organizations, efficacy and right emotional behaviors and cognitions of the individual/s. Employees found with positive association between agreeableness, extroversion \& conscientiousness and affective commitment are referred more likely to be committed to the organization and decreasing the cost of turnover and which costs organizations huge amounts of expenditure every year in several ways and disturbs in general for an organiza- 
tion/s when an employee/s leaves. While an organization able to recruit or select employee/s considerably that score moderate to high on aforesaid personality traits and employees with high level of emotional stability, self-efficacy and organizational commitment tend to be significant for the practitioners.

\section{Fund}

This research was supported by NCDB Co-operative Research Fellowship, the Co-operative Research Fellowship Management Committee, National Co-operative Development Board (NCDB), Ministry of Co-operative and Poverty Alleviation, Government of Nepal, Pulchowk, Laitpur, Nepal.

\section{Conflicts of Interest}

The authors declare no conflicts of interest regarding the publication of this paper.

\section{References}

[1] Sears, G.J. and Rowe, P.M. (2003) A Personality-Based Similar-to-Me Effect in the Employment Interview: Conscientiousness, Affect-Versus Competence-Mediated Interpretations, and the Role of Job Relevance. Canadian Journal of Behavioural Science/Revue Canadienne des Sciences du Comportment, 35, 13-24.

[2] John, O.P. and Srivastava, S. (1999) The Big Five Trait Taxonomy: History, Measurement, and Theoretical Perspectives. Handbook of Personality: Theory and Research, 2, 102-138.

[3] Somers, M.J. (1995) Organizational Commitment, Turnover and Absenteeism: An Examination of Direct and Interaction Effects. Journal of Organizational Behavior, 16, 49-58. https://doi.org/10.1002/job.4030160107

[4] Jaros, S.J. (1997) An Assessment of Meyer and Allen's (1991) Three-Component Model of Organizational Commitment and Turnover Intentions. Journal of Vocational Behavior, 51, 319-337. https://doi.org/10.1006/jvbe.1995.1553

[5] Jehanzeb, K., Rasheed, A. and Rasheed, M.F. (2013) Organizational Commitment and Turnover Intension: Impact of Employee's Training in Private Sector of Saudi Arabia. International Journal of Business and Management, 8, 79-90. https://doi.org/10.5539/ijbm.v8n8p79

[6] Zayas-Ortiz, M., Rosario, E., Marquez, E. and Colón Gruñeiro, P. (2015) Relationship between Organizational Commitment and Organizational Citizenship Behaviour in a Sample of Private Banking Employees. International Journal of Sociology and Social Policy, 35, 91-106. https://doi.org/10.1108/IJSSP-02-2014-0010

[7] Akinbobola, O.I. (2011) Conflict in Human Capital Relationships: The Effect of Job Satisfaction on Job Involvement in a Workplace. International Journal of Social Science and Humanity, 1, 92-95. https://doi.org/10.7763/IJSSH.2011.V1.16

[8] Jung. G. (1926-1954) Analytical Psychology and Education: Three Lectures. In: Jung, C.G., Ed., Volume 17, Collected Works, The Development of Personality, Pantheon, New York, 65-132.

[9] Donnellan, M.B., Oswald, F.L., Baird, B.M. and Lucas, R.E. (2006) The Mini-IPIP Scales: Tiny-Yet-Effective Measures of the Big Five Factors of Personality. Psychological Assessment, 18, 192-203. https://doi.org/10.1037/1040-3590.18.2.192 
[10] Gelade, G.A., Dobson, P. and Gilbert, P. (2006) National Differences in Organizational Commitment: Effect of Economy, Product of Personality, or Consequence of Culture? Journal of Cross-Cultural Psychology, 37, 542-556.

[11] Church, A.T. (2000) Culture and Personality: Toward an Integrated Cultural Traits.

[12] Meyer, J.P. and Allen, N.J. (1997) Commitment in the Workplace: Theory, Research, and Application, Sage.

[13] Allen, N.J. and Meyer, J.P. (1991) The Measurement and Antecedents of Affective, Continuance and Normative Commitment to the Organization. Journal of Occupational Psychology, 63, 1-18. https://doi.org/10.1111/j.2044-8325.1990.tb00506.x

[14] Hackney, C.W. (2012) Personality, Organizational Commitment, and Job Search Behavior: A Field.

[15] Bandura, A. (1995). Self-Efficacy in Changing Societies. New York: Cambridge University Press. Banking Employees. International Journal of Sociology and Social Policy, 35. https://doi.org/10.1017/CBO9780511527692

[16] Bandura, A. (1977) Self-Efficacy: Toward a Unifying Theory of Behavioral Change. Psychological Review, 84, 191-215. https://doi.org/10.1037/0033-295X.84.2.191

[17] Bandura, A. (1997) Self-Efficacy: The Exercise of Control. Freeman, New York.

[18] Luszczynska, A. and Schwarzer, R. (2005) Social Cognitive Theory. In: Conner, M. and Norman, P., Eds., Predicting Health Behavior, 2nd Edition, Open University Press, Buckingham, 27-169.

[19] Gungor, F., Kurt, H. and Ekici, G. (2013) The Relationship between Personality Types and Self-Efficacy Perceptions of Students Teachers. Procedia Social and Behavioral Science, 116, 786-790.

[20] Bakker, A.B., Demerouti, E. and Brummelhuis, L.L. (2012) Work Engagement, Performance and Active Learning: The Role of Conscientiousness. Journal of Vocational Behavior, 80, 555-564. https://doi.org/10.1016/j.jvb.2011.08.008

[21] Laguna, M., Razmus, W. and Aliski, A. (2017) Dynamic Relationships between Personal Resources and Work Engagement in Entrepreneurs. Journal of Occupational and Organizational Psychology, 90, 248-269.

https://doi.org/10.1111/joop.12170

[22] Kossowska, M. and Laguna, M. (2018) Personality, Job Resources, and Self-Efficacy as Preditors of Volunteer Engagement in Non-Governmental Organizations. Journal for Perspectives of Economic Political and Social Integration, 24, 69-89. https://doi.org/10.2478/pepsi-2018-0003

[23] Farrukh, M., Ying, C. and Mansori, S. (2017) Organizational Commitment: An Empirical Analysis of Personality Traits. Journal of Work-Applied Management, 9, 18-34. https://doi.org/10.1108/JWAM-12-2016-0026

[24] Norman, W.T. (1963) Toward an Adequate Taxonomy of Personality Attributes: Replicated Factor Structures in Peer Nomination Personality Ratings. Journal of Abnormal and Social Psychology, 66, 571-583. https://doi.org/10.1037/h0040291

[25] McCrae, R.R. and Costa, P.T. (1999) A Five-Factor Theory of Personality. In: Pervin, L.A. and John, O.P., Eds., Handbook of Personality, 2 Edition, The Guilford Press, New York.

[26] Subedi, K.P. (2015) The Study of Personality Traits, Job Involvement and Job Satisfaction of the Civil Service Employee of Nepal. Unpublished PhD Thesis, Pacific University, Udaipur.

[27] Erdheim, J., Wang, M. and dan Zickar, M.J. (2006) Linking the Big Five Personality Constructs to Organizational Commitment. Personality and Individual Differences, 
41, 959-970. https://doi.org/10.1016/j.paid.2006.04.005

[28] Zimmerman, J. (2010) At GE and Intel. Journal of Business Case Studies, 6, 77-82.

[29] Eckhardt, A., Laumer, S., Maier, C. and Weitzel, T. (2016) The Effect of Personality on IT Personnel's Job Related Attitudes: Establishing a Dispositional Model of Turnover Intention across IT Job Types. Journal of Information Technology, 31, 1-19. https://doi.org/10.1057/jit.2014.27

[30] Zimmerman, R.D. (2008) Understanding the Impact of Personality Traits on Individuals Turnover Decisions: A Meta-Analytic Path Model, Personnel Psychology, 61, 309-348. https://doi.org/10.1111/j.1744-6570.2008.00115.x

[31] Furnham, A., Forde, L. and Ferrari, K. (1999) Personality and Work Motivation. Personality and Individual Differences, 26, 1035-1043. https://doi.org/10.1016/S0191-8869(98)00202-5

[32] Becker, H.S. (1960) Notes on the Concept of Commitment. American Journal of Sociology, 66, 32-40. https://doi.org/10.1086/222820

[33] Regmi, M.P. (1982) Interpretation of the Gurung Dreams. Psychologia, 28, 35-45.

[34] Regmi, M.P. (1982) The Personality Structure of Nepalese Gurungs. Unpublished Doctoral Thesis, University of Saugar, Saugar.

[35] Regmi, M.P. (1991) The Gurungs: Thunder of Himal. Nirala Publications, Daryaganj, New Delhi.

[36] Spagnoli, P. and Caetanom, A. (2012) Personality and Organizational Commitment: The Mediating Role of Job Satisfaction during Socialization. Career Development International, 17, 255-275. https://doi.org/10.1108/13620431211241081

[37] Tziner, A., Shultz, T. and Fisher, T. (2008) Justice, Leader-Member Exchange, and Job Performance: Are Their Relationships Mediated by Organizational Cultures? Psychological Reports, 103, 516-526, 2008. https://ssrn.com/abstract=1311260

[38] Choi, D., Oh, I.-S. and Colbert, A. (2015) Understanding Commitment at Work: A Meta Analytic Examination of the Roles of the Five-Factor Model of Personality and Culture. Journal of Applied Psychology, 100, 1542-1567.

[39] Stewart, G.L. and Nandkeolyar, A.K. (2006) Adaptation and Intra Individual Variation in Sales Outcomes: Exploring the Interactive Effects of Personality and Environmental Opportunity. Personnel Psychology, 59, 307-332. https://doi.org/10.1037/apl0000014

[40] Ganu, D. and Kogutu, C. (2014) Effect of the Big Five Personality Traits on Job Satisfaction and Organizational Commitment in the Healthcare Industry: The Case of Kenya. American Journal of Health Sciences, 5, 145-154. https://doi.org/10.19030/ajhs.v5i2.8964

[41] Michaud, M. (2013) Personality a Key Factor in Healthcare Use. http://www.urmc.rochester.edu/news/story/index.cfm?id=3939

[42] Wilson, K., Kickul, J. and Marlino, D. (2007) Gender, Entrepreneurial Self-Efficacy, and Entrepreneurial Career Intentions: Implications for Entrepreneurship Education. Entrepreneurship Theory and Practice, 13, 387-406. https://doi.org/10.1111/j.1540-6520.2007.00179.x

[43] Finegan, J.E. (2000) The Impact of Person and Organizational Values on Organizational Commitment. Journal of Occupational and Organizational Psychology, 73, 149-169. https://doi.org/10.1348/096317900166958

[44] Agrawal, G.R. (1977) Management and Development. CEDA, Kathmandu.

[45] Gautama, T. (2004) Organizational Commitment in Nepal. Unpublished PhD, The- 
sis, Faculty of Management, Tribhuvan University, Kathmandu.

[46] Koirala, U. (1989) Workers Participation in Management. Unpublished PhD Thesis, University of Allahabad, Allahabad.

[47] Upadhyay, N.P. (1981) Personnel Management in Manufacturing Public Enterprises in Nepal. Unpublished PhD Thesis, Panjab University, Panjab.

[48] Gautam, T., van Dick, R. and Wagner, U. (2001) Organizational Commitment in Nepalese Setting. Asian Journal of Social Psychology, 4, 239-248. https://doi.org/10.1111/1467-839X.00088

[49] Kumar, K. and Bakhshi, A. (2010) The Five-Factor Model of Personality and Organizational Commitment: Is There Any Relationship. Humanity and Social Sciences Journal, 5, 25-34.

[50] Cui, C. (2010) The Relationship among Personality Traits, Job Design Characteristics and Organizational Commitment: An Empirical Study of Organizations in China. Master Thesis, The University of Waikato, Waikato.

[51] Chandel, J.K., Sharma, S.K. and Bansal, S.P. (2011) Linking the Big Five Personality Domains to Organizational Commitment. International Journal of Research in Commerce, IT and Management, 1, 19-24.

[52] Sharma, L. (2012) Introduction to Co-Operative, Divya Deurali Prakashan Pvt. Ltd., Bagbazar, Kathmandu, Nepal. Statistics of Cooperative Enterprises, Department of Cooperative, Ministry of Cooperative and Poverty of Alleviation, Government of Nepal.

[53] Panaccio, A. and Vandenberghe, C. (2012) Five-Factor Model of Personality and Organizational Commitment: The Mediating Role of Positive and Negative Affective States. Journal of Vocational Behavior, 80, 647-658. https://doi.org/10.1016/j.jvb.2012.03.002

[54] Lzzati, U.A., Suhariadi, F. and Hadi, C. (2015) Personality Trait as Predictor of Affective Commitment. Open Journal of Sciences, 3, 34-39. https://doi.org/10.4236/jss.2015.36008

[55] Shabahang, M.J. and Amani, M. (2016) The Relationship between Personality Factors and Organizational Commitment of Iranian Primary School Principals. International Journal of Psychology and Educational Studies, 3, 50-59. https://doi.org/10.17220/ijpes.2016.03.006

[56] Brislin, R.W. (1970) Back-Translation for Cross-Cultural Research. Journal of Cross-Cultural Psychology, 1, 185-216.

[57] Choi, D., Oh, I.-S. and Colbert, A.E. (2015) Understanding Organizational Commitment: A Meta-Analytic Examination of the Roles of the Five-Factor Model of Personality and Culture. Journal of Applied Psychology, 100, 1542-1567. https://doi.org/10.1037/apl0000014

[58] Matzler, K., Renzl, B., Mooradian, T., Von Krogh, G. and Mueller, J. (2011) Personality Traits, Affective Commitment, Documentation of Knowledge, and Knowledge Sharing. The International Journal of Human Resource Management, 22, 296-310. https://doi.org/10.1080/09585192.2011.540156

[59] Aryal, N. and Panta, S.B. (2015) Financial Literacy and Co-Operatives Sustainability: A Study among the Executive Members of the Co-Operatives. International Journal of Community and Co-operative Studies, 3, 17-29.

http://www.encyclopedia.com/people/medicine/psychology-and-psychiatry-biograp hies/carl-gustav-jung

[60] Adhikari, D.R. and Gautam, D.K. (2010) Human Resource Development for Per- 
formance Management. International Journal of Productivity and Performance, 49, 306-324. https://doi.org/10.1108/17410401011038883

[61] Adhikari, D.R. and Gautam, D.K. (2011) Employees Commitment and Organizational Performance in Nepal: A Typological Framework. SEBON Journal, 5, 1-17.

[62] Basnet, D.M., Birla, M. and Regmi, M.P. (2019) Impact of Emotional Stability on Self-Efficacy and Organizational Commitment of Employees' at Nepalese Saving \& Credit Co-Operative Societies (SACCOS) Financial Institutions. Global Journal of Human Social Sciences: Arts \& Humanities-Psychology, 19, 17-29. 